\title{
PERFORMANCE DESIGN OF ACID GAS REMOVALUNIT ON PERTAMINA - MEDCO E\&P TOMORI SULAWESI - INDONESIA
}

\author{
Kristinah Haryani \\ DepartemenTeknik Kimia, FakultasTeknik, UniversitasDiponegoro, \\ Jl. Prof. Soedarto, SH, Kampus Undip Tembalang, Semarang, Indonesia 50275 \\ *) krisyani83@yahoo.co.id \\ *)Corresponding Author
}

\begin{abstract}
Natural gas is a gaseous fossil fuel that contain primarily of main components, namely methane $\left(\mathrm{CH}_{4}\right)$. Natural gas contains some impurities such as hydrogen sulfide $\left(\mathrm{H}_{2} \mathrm{~S}\right)$, carbon dioxide $\left(\mathrm{CO}_{2}\right)$, water vapor $\left(\mathrm{H}_{2} \mathrm{O}\right)$, and heavier hydrocarbons such as mercaptans or condensate $\left(\mathrm{C}_{5}+\right)$.Acid gases need to be removed due to several factors, such as a healthy hazard, at the concentrations of $0.13 \mathrm{ppm} \mathrm{H}_{2} \mathrm{~S}$ that can be perceived by smell, and to prevent corrosion problemsAcid gas removal unit (AGRU) is the process of removal acid gas $\left(\mathrm{CO}_{2}\right.$ and $\left.\mathrm{H}_{2} \mathrm{~S}\right)$ to fulfill the specifications of the desired product gas sales. In Senoro CPP, the process used is amine treating by aMDEA absorbent material (activated Methyl Amine Diethanol).In order to simulate the process as accurate as possible, model phase selection DBR amine package was selected. Trial simulation is used to obtain the flow rate and purity of the product is optimal sweet gas. Variable experiments are feed gas temperatur inlet contactor (1), feed gas flowrate inlet contactor (2), temperature amine inlet contactor (3) and amine strength (4). According to the results of simulation, can be concluded as follows. There is no big different between design and simulation except $\mathrm{CO}_{2}$ in sweet gas. It is because of using MDEA while operating simulation and some parameters will be influence some result.
\end{abstract}

Keywords : $\mathrm{CO}_{2}, \mathrm{H}_{2} \mathrm{~S}, \mathrm{MDEA}$, HYSYS Simulation

\section{Background}

Natural gas is a gaseous fossil fuel that contain primarily of main components, namely methane $\left(\mathrm{CH}_{4}\right)$. Natural gas contains some impurities such as hydrogen sulfide $\left(\mathrm{H}_{2} \mathrm{~S}\right)$, carbon dioxide $\left(\mathrm{CO}_{2}\right)$, water vapor $\left(\mathrm{H}_{2} \mathrm{O}\right)$, and heavier hydrocarbons such as mercaptans or condensate $\left(\mathrm{C}_{5}+\right)$. Natural gas with $\mathrm{H}_{2} \mathrm{~S}$ or other sulfur compounds (such as COS, $\mathrm{CS}_{2}$ and mercaptans) called acid gas, while gas without $\mathrm{CO}_{2}$ and $\mathrm{H}_{2} \mathrm{~S}$ called as sweet gas. The existence of $\mathrm{H}_{2} \mathrm{~S}$ compounds, sulfur compounds and $\mathrm{CO}_{2}$ are not wanted at the natural gas composition so that the presence of these compounds need to be eliminated. Acid gases need to be removed due to several factors, such as a healthy hazard, at the concentrations of $0.13 \mathrm{ppm} \mathrm{H}_{2} \mathrm{~S}$ that can be perceived by smell, and to prevent corrosion problems. Besides increasing the calor value of the gas (Abdel and Mohamed, 2003).

The plant that produced Sales gas has certain specifications in according by the agreement with the buyer. The specification of sales gas has strict specifications, the specification is maximum of 0.25 grain / 100SCF of $\mathrm{H}_{2} \mathrm{~S}$ (GPA (1968), Std. 2265 and GPA (1986 ), Std. 2377) and a maximum of $1-3 \% \mathrm{~mol} \mathrm{CO}_{2}$ (GPA (1990), Std. 2261). Feed inSenoro CPP containing $\mathrm{H}_{2} \mathrm{~S}$ (1000 ppmv) and $\mathrm{CO}_{2}(5 \%)$. Senoro CPP has been set the standard of gas sales by its own according the agreement with the buyer that $\mathrm{H}_{2} \mathrm{~S}$ content of less than 1 ppmv and $\mathrm{CO}_{2}$ levels less than 50 ppmv.

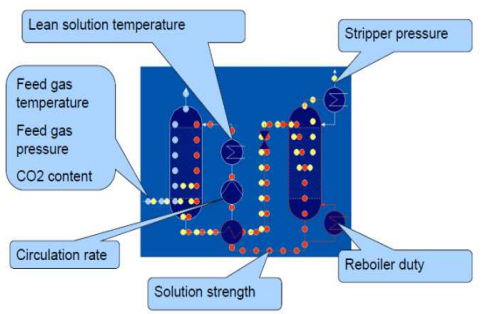

Figure 1.Process of AGRU System

Acid gas removal unit (AGRU) is the process of removal acid gas $\left(\mathrm{CO}_{2}\right.$ and $\left.\mathrm{H}_{2} \mathrm{~S}\right)$ to fulfill the specifications of the desired product gas sales. In Senoro CPP, the process used is amine treating by aMDEA absorbent material (activated Methyl Amine Diethanol). Acid gas 
removal process with MDEA, there are two major units, namely amine contactor which serves to absorb the acid gas by utilizing MDEA to absorbs acid gas by counter-current system of mass transfer. The second, amine regenerators that serve to regenerate amine for reuse in the amine contactor

Some parameters that must be considered in the process of AGRU is the operating condition contactor and regenerator. In the contactor, in order to avoid evaporation, the pressure contactor operation should be above 100 psi (7 bar) above the bubble point of the liquid, and the entire unit must operate at least 50 psi (3.4 bar) above the bubble point. the contactor column's viscosity should not exceed $2 \mathrm{cP}$ to ensure the separation of amine or hydrocarbon well. Even so, the expected normal concentration of the amine in a hydrocarbon stream leaving the unit was about $100 \mathrm{ppmw}$ At the regenerator column, the temperature and pressure will be set about $260{ }^{\circ} \mathrm{Fand} 21$ psig to evaporate $\mathrm{H}_{2} \mathrm{~S}$ and $\mathrm{CO}_{2}$ 's rich amine out of amine contactor.

Processes design that be used in the Acid Gas Removal Unit (AGRU)'s Senoro CPP is technology BASF (Badische Aniline and Soda Fabrik) to the system used is the amine system and the absorbent material used is a solution aMDEA (activated Methyl Amine Diethanol).

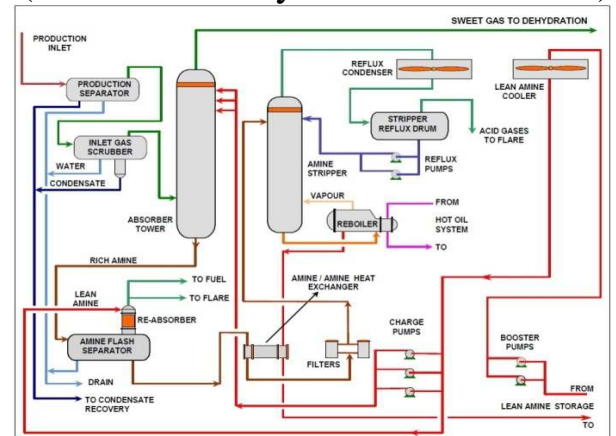

Figure 2 Main Process of Acid Gas Removal Unit

The Main Process of AGRU and amine treating is contact between sour gasand amine (removal $\mathrm{CO}_{2}$ and $\mathrm{H}_{2} \mathrm{~S}$ ) on amine contactor and aMDEA regeneration. The process working is showed by figure 2 and figure 3 .

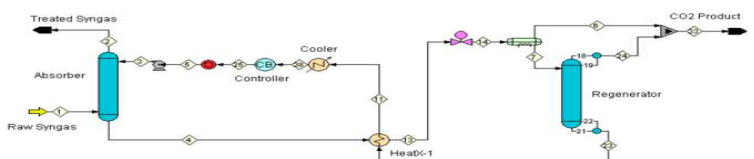

Figure 3 Symulation HYSYS of AGRU System

\section{Method}

There are several steps required, as follows figure 4

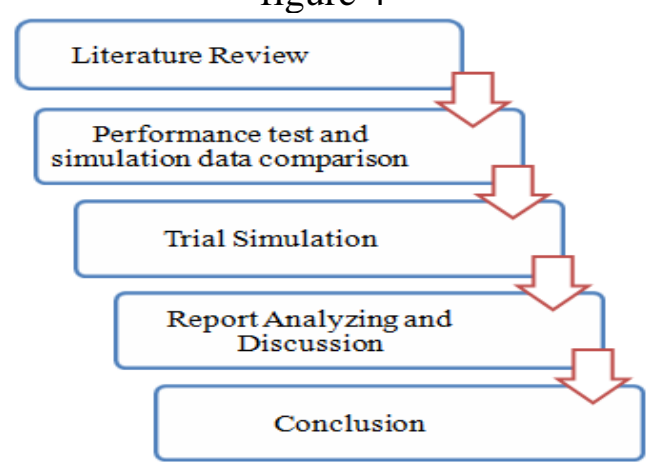

Figure 4 Flow Diagramof Assignment Report

\section{Literature Review}

Literature Review is used to collect information from several sources such as P\&ID, PFD, journals, etc. The summary from literature will be the data source for completing this assignment report. The method that will use is retrieving design data each equipment, analysis result of sweet gas, $\mathrm{CO}_{2}$ loading and acid loading. Design data that be used is normal rich case design because it is the most approach actual data.

\section{Process Description of Hysys Simulation for Acid Gas Removal Unit}

In order to simulate the process as accurate as possible, model phase selection DBR amine package was selected. Feed is sour gas entered through the bottom of contactor column and aMDEA as absorbent entry through the contactor column top in order to contact each other. aMDEA absorb $\mathrm{H}_{2} \mathrm{~S}$ and $\mathrm{CO}_{2}$ contained in sour gas at temperature $90{ }^{\circ} \mathrm{F}$ and Pressure 900 Psig. The Outlet of amine contactor over head column is sweet gas and the bottom 
column is rich amine. Then, the pressure will be reduce by valve until 105 Psig.

Rich amine will entry to amine flash drum to be separated between rich amine and acid gas that carry over. The outlet of amine flash drum bottom head go through heat exchanger to exchange heat and raise temperature in order to get the temperature $246{ }^{\circ} \mathrm{F}$ and pressure $20 \mathrm{psig}$ In regenerator, the heating process is done by reboiler. Reboiler temperature is maintained at $264.2{ }^{\circ} \mathrm{F}$ to evaporate acid gas as well to keep amine is not degraded. Acid gas that has been separated and become the top result will come to acid gas conversion unit (AGCU). Rich amine that has been separated with acid gas called as lean amine. It will go through bottom amine regenerator and being recycle into amine contactor.

Lean amine pumped by booster pump in delta pressure 100 psig to the heat exchanger so the heat will exchange and cooling temperature up to $163^{\circ} \mathrm{F}$. Lean amine will be channeled toward $\mathrm{s}$ cooler and circulation pump to adjust temperature and pressure above the entry condition as well as contactor column at temperature $130^{\circ} \mathrm{F}$ and pressure $899 \mathrm{psig}$. Most lean amine will be split flow rate is that $50 \%$ towards to contactor column and the other to regenerator column.

Trial simulation is used to obtain the flow rate and purity of the product is optimal sweet gas. Variable experiments are feed gas temperatur inlet contactor (1), feed gas flowrate inlet contactor (2), temperature amine inlet contactor (3) and amine strength (4).

\section{Table 1 Variables of Trial Simulation}

\begin{tabular}{|c|c|c|c|c|}
\hline Variable & $\mathbf{1}$ & $\mathbf{2}$ & $\mathbf{3}$ & $\mathbf{4}$ \\
\hline Unit Measurement & ${ }^{\mathbf{0}} \mathbf{F}$ & $\mathbf{M M S C F D}$ & ${ }^{\mathbf{0}} \mathbf{F}$ & $\mathbf{\%} \mathbf{\text { wt }}$ \\
\hline \multirow{6}{*}{ Variables } & 90 & 150 & 90 & 38 \\
\cline { 2 - 5 } & 100 & 160 & 100 & 39 \\
\cline { 2 - 5 } & 110 & 170 & 110 & 40 \\
\cline { 2 - 5 } & 120 & 180 & 120 & 41 \\
\cline { 2 - 5 } & 130 & 190 & 130 & 42 \\
\cline { 2 - 5 } & 140 & & 140 & 43 \\
\cline { 2 - 5 } & 150 & & 150 & 44 \\
\cline { 2 - 5 } & & & & 45 \\
\hline
\end{tabular}

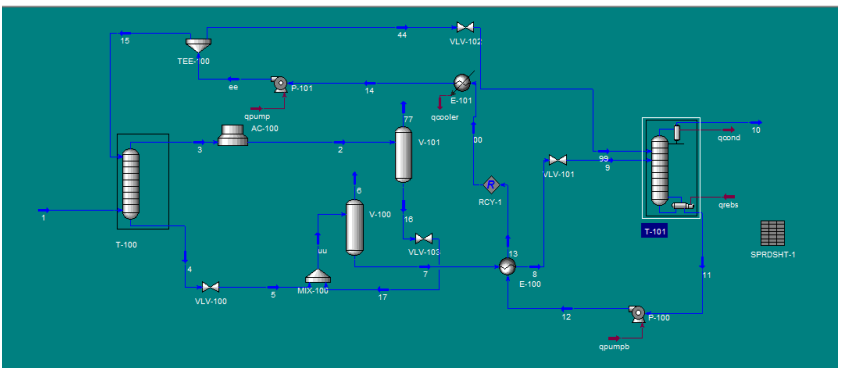

Figure 5 Simulation Hysys Acid Gas Removal Unit

\section{Result And Discussion}

\section{Effect of Flow rate Feed Gas Inlet Contactor Column}

Figure 6 Shows the change in concentration of $\mathrm{H}_{2} \mathrm{~S}$ and $\mathrm{CO}_{2}$ in the sweet gas on top of absorber column versus the change of feed gas flow rate. In accordance with Figure 4, the increase of feed gas flow rate will increase the concentration of $\mathrm{H}_{2} \mathrm{~S}$ and $\mathrm{CO}_{2}$. Although, the concentration of $\mathrm{H}_{2} \mathrm{~S}$ is on spec.

The simulation is done by increasing of feed gas flow rate of 150 MMsfd into $190 \mathrm{MMscfd}$ by multiple 10 degrees. The concentration and temperature of amine into absorber column is constant. Based on figure, the increasing of feed gas flow rate into absorber column showed that the concentration of acid gas $\left(\mathrm{H}_{2} \mathrm{~S}\right.$ and $\left.\mathrm{CO}_{2}\right)$ is increased. Thus, with the same of concentration and flow rate amine inlet to absorber column, the reaction between amine and acid gas may occurred until amine is saturated. As the result, acid gas inlet column contactor is not fully absorb by amine so that the concentration of acid gas product in the top absorber is increase by increasing of feed gas flow rate.

Figure 6 show that the $\mathrm{H}_{2} \mathrm{~S}$ concentration product is on spec. The specification of $\mathrm{H}_{2} \mathrm{~S}$ concentration is less than $1 \mathrm{ppm}$. In other hand, the concentration of $\mathrm{CO}_{2}$ has bigger concentration than so that not fulfill specification. The Solvent that be used of simulation is MDEA. It caused the bigger concentration of $\mathrm{CO}_{2}$. The reaction between MDEA and $\mathrm{CO}_{2}$ is : 


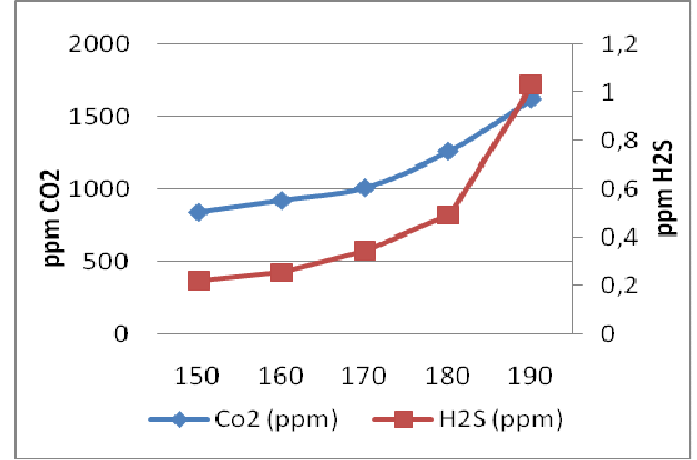

Figure 6.The Correlation Between Flow Rate Feed Gas and Acid Gas Concentration Product

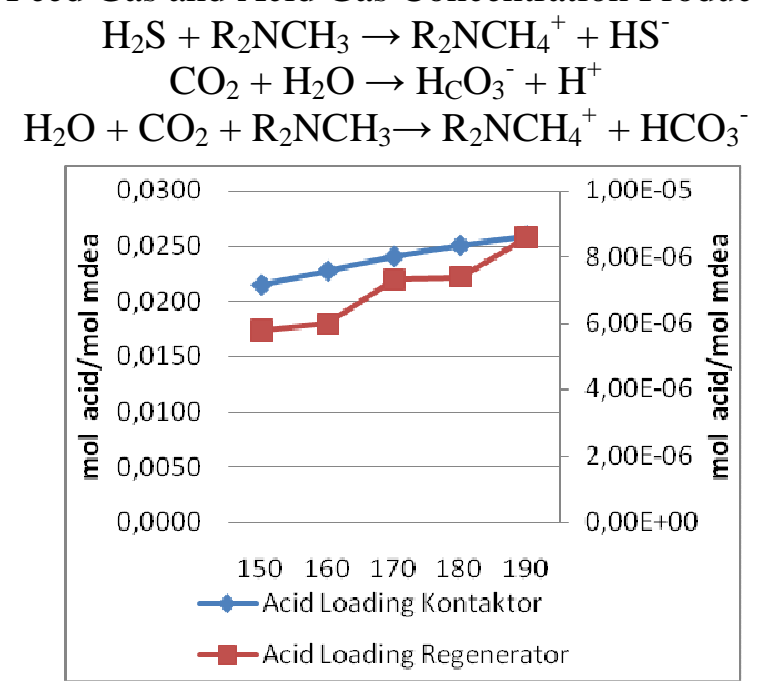

Figure 7The Correlation of Flow Rate Feed

Gas and Acid Loading in Contactor and

Regenerator column

MDEA, however, cannot react directly with $\mathrm{CO}_{2}$ to form carbamate. In MDEA solutions, the reaction with $\mathrm{CO}_{2}$ forms bicarbonate, and the $\mathrm{CO}_{2}$ reaction rate is significantly slower than that of $\mathrm{H}_{2} \mathrm{~S}$ with MDEA; therefore, MDEA generally exhibit greater selectivity for $\mathrm{H}_{2} \mathrm{~S}$ in the presence of $\mathrm{CO}_{2}$ (NREL,2009). It cause the $\mathrm{CO}_{2}$ absorption process has been slow and resulted in the concentration of $\mathrm{CO}_{2}$ is not qualified product. To accelerate the reaction, it needs activator in solvent. Activator which can be used are piparazine. Piperazine is a promoter that is highly reactive towards $\mathrm{CO}_{2}$; thus, when added to the MDEA solution, the solution's capability for $\mathrm{CO}_{2}$ absorption can be significantly enhanced. The optimum piparazine content in MDEA was 5\% in 45 wt\% MDEA (Alvis, 2012).

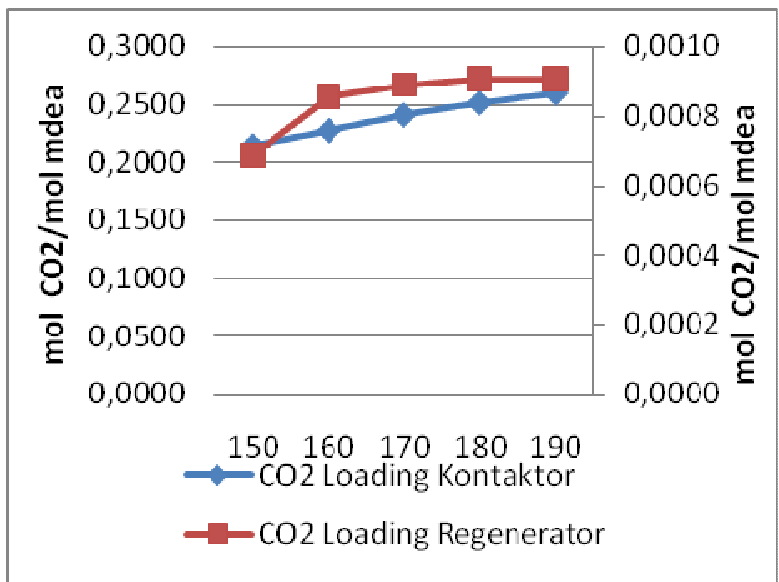

Figure 8.The Correlation of Flow Rate Feed Gas and $\mathrm{CO}_{2}$ Loading in Contactor and Regenerator column

Figure 7 and Figure 8 show how is the effect of feed gas flow rate versus acid gas and $\mathrm{CO}_{2}$ loading contactor and regenerator. From that figure, we can conclude that the increasing of flow rate make a increasing acid gas loading and $\mathrm{CO}_{2}$ loading both contactor and regenerator. It means that acid gas on rich amine and lean amine increasing by increase of flow rate. Increasing flow rate means increasing total composition of acid gas to contactor. Amine will absorb acid gas higher than before, So that it increasing acid gas and $\mathrm{CO} 2$ loading generally.

\section{Effect of Temperature Feed Gas Inlet Contactor Column}

Knowing the influence of temperature increase in feed gas, the feed gas temperature has increased at $90{ }^{\circ} \mathrm{F}$ to $150^{\circ} \mathrm{F}$. With the condition, the concentration of amine and amine temperature constant at $42 \%$ wt and $130^{\circ} \mathrm{F}$.Figure 4.4.Shows the change in concentration of $\mathrm{H}_{2} \mathrm{~S}$ and $\mathrm{CO}_{2}$ in the sweet gas versus temperature change of feed gas coming 
contactor column. From the pictures, it is known that there is no significant changes in the concentrations of $\mathrm{H}_{2} \mathrm{~S}$ in the product. However if the incoming feed gas contactor column at temperatures of $120^{\circ} \mathrm{F}$ to $150{ }^{\circ} \mathrm{F}$ concentrations $\mathrm{CO}_{2}$ in the product will increase.

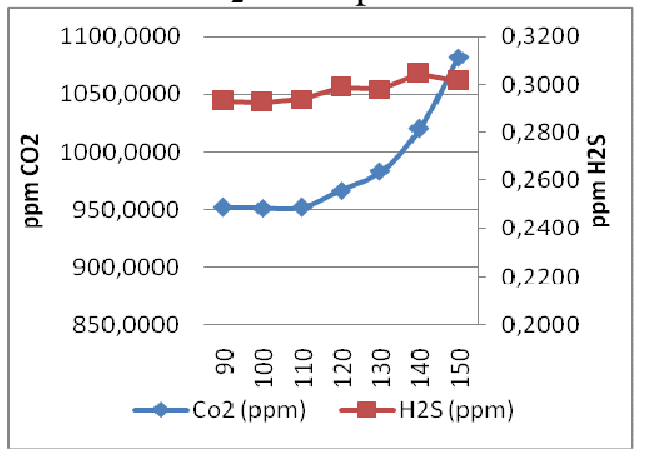

Figure 9The Correlation Between Temperature Feed Gas and Acid Gas Concentration Product

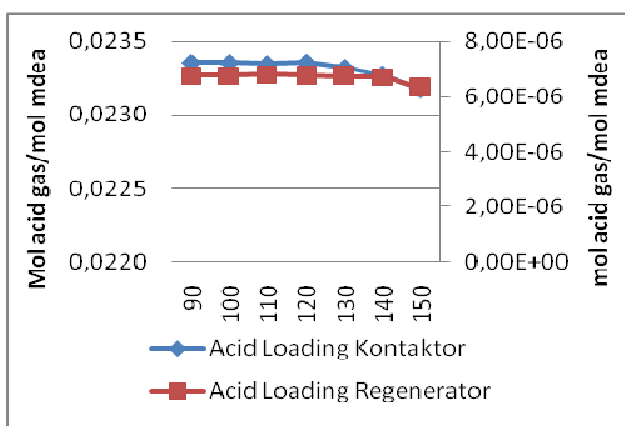

Figure 10The Correlation of Temperature Feed Gas and Acid Loading in Contactor and Regenerator column

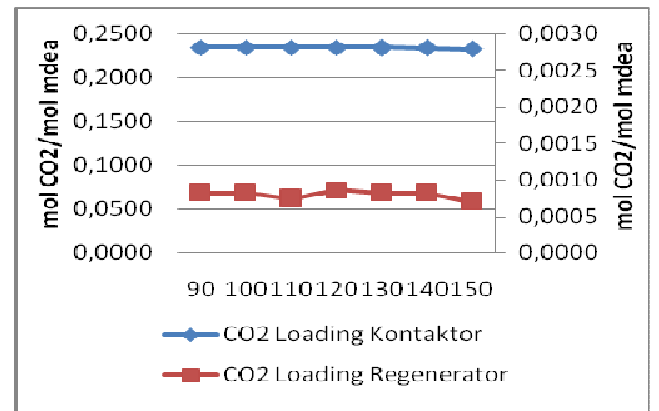

Figure 11The Correlation of Temperature Feed Gas and $\mathrm{CO}_{2}$ Loading in Contactor and Regenerator column

Based on Mokhatab et al in the Handbook of Natural Gas Transmission and Processing: Principles and Practices, in operating the absorber column in the amine unit, the temperature difference between the inlet feed gas temperatures under the column with the lean amine temperature top of the column is about $10-15{ }^{\circ} \mathrm{F}$. It avoids condensation of hydrocarbons.

Condensed hydrocarbons accumulated in the system may promote foaming. In the simulation, the lean amine temperature into the contactor is $130^{\circ} \mathrm{F}$ which means that the temperature of the inlet gas feed maximum column is $115^{\circ} \mathrm{F}$ to avoid condensation of hydrocarbons. Based on the figure 9 , In 120$150^{\circ} \mathrm{F}$ temperature $\mathrm{H}_{2} \mathrm{~S}$ and $\mathrm{CO}_{2}$ concentration increased concentration caused by the presence of hydrocarbons condensation so that reaction with the amine is not running optimally.

In Figure 10 and Figure 11 shows the acid loading and $\mathrm{CO}_{2}$ loading on the column and the column regenerator contactor have the same tendency, there is no significant difference. Based on the simulation, the temperature of feed gas coming contactor column did not change significantly. Operations should be carried out at a lower temperature is $90{ }^{\circ} \mathrm{F}$ $110^{\circ} \mathrm{F}$.

\section{Effect of Amine Strength}

Figure 12Shows the change of $\mathrm{H}_{2} \mathrm{~S}$ and $\mathrm{CO}_{2}$ concentration out of top product in absorber column versus changes of amine concentration inlet contactor column. The increase in amine concentration cause a decrease in the concentration of $\mathrm{H}_{2} \mathrm{~S}$ and $\mathrm{CO}_{2}$ in gas sweet products.

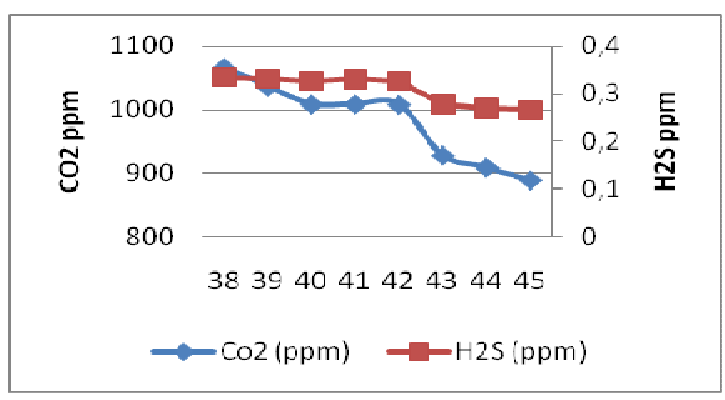

Figure 12The Correlation Between Amine Strength and Acid Gas Concentration Product 
The Simulation is done by increasing concentration of amine at $38 \%$ up to $45 \%$ by multiple 1 degrees. Based on figure, the higher concentration of amine indicate the much amine react and contact with acid gas. Thus, The bigger concentration of amine has the bigger absorption capacity. So that, the higher concentration of amine is fully absorb acid gas in contactor column because of the higher absorption capacity. Thus, decreasing of concentration $\mathrm{H}_{2} \mathrm{~S}$ and $\mathrm{CO}_{2}$ in product (Mahadipoor, 2015).Increasing the solution concentration can generally reduce the circulation rate, thereby reducing the plant cost; however, in order to avoid equipment corrosion, the solution concentration should not exceed the upper limit recommended for the solvent type (Zurloetc, 2013).

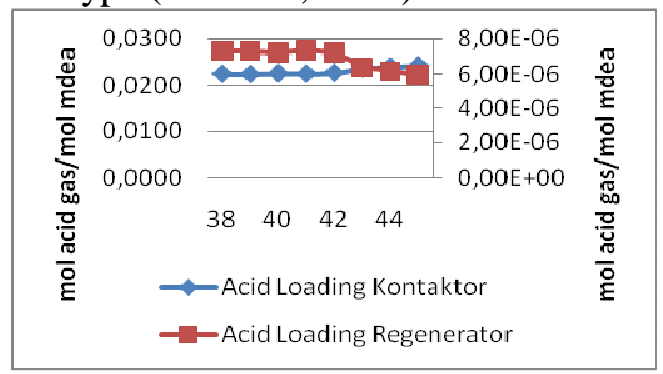

Figure 14The Correlation of Amine Strength and Acid Loading in Contactor and Regenerator column

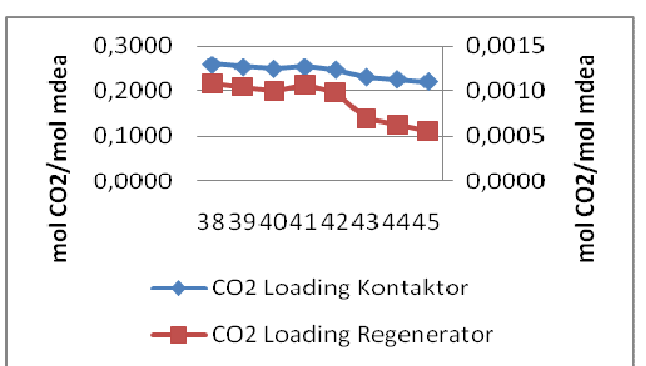

Figure 15The Correlation of Amine Strength and $\mathrm{CO}_{2}$ Loading in Contactor and Regenerator column

Figure 14 and Figure 15 shows the change of acid gas loading and loading $\mathrm{CO}_{2}$ in rich amine and lean amine versus amine strength. Based on Figure 14 Acid gas loading in the absorber contactors tend to be stable. The increasing of amine strength means more acid gas absorb so that rich amine contains more acid gas. Based on Figure $15 \mathrm{CO}_{2}$ loading in the column and the column contactors regenerator slowly decreased, this is because the amine reacts faster to $\mathrm{H}_{2} \mathrm{~S}$ than $\mathrm{CO}_{2}$. Rich amine contain more $\mathrm{H}_{2} \mathrm{~S}$ than $\mathrm{CO}_{2}$, and some of $\mathrm{CO}_{2}$ will go through to sweet gas. The increase in the concentration of amine in the system provides a positive impact, in this case the amine concentration is maintained at $42-43 \% \mathrm{wt}$ provide optimum product concentration changes significantly. To ensure optimum amine concentrations can see some parameters, the parameter is (Satyadileep et al, 2013).:

- Acid gas concentration in sweet gas,

- Steam consumption rate,

- Amine circulation rate,

- Rich amine loading and lean amine loading.

\section{Effect of Amine Temperature Inlet Column Contactor}

To determine the effect of temperature rise in the absorber column operation, amine temperature has increased at $90{ }^{\circ} \mathrm{Fup}$ to $150{ }^{\circ} \mathrm{F}$. The simulation condition is temperature sour gas into the absorber column constant at $90^{\circ} \mathrm{F}$. Figure 4.10 shows the change in concentration of $\mathrm{H}_{2} \mathrm{~S}$ and $\mathrm{CO}_{2}$ in a sweet gas product out of the column versus temperature changes amine absorber. Figure 16 show that the increase in temperature will decrease $\mathrm{H}_{2} \mathrm{~S}$ and $\mathrm{CO}_{2}$ concentration of acid gas due to decreasing until relatively constant (Lunsford,2006).

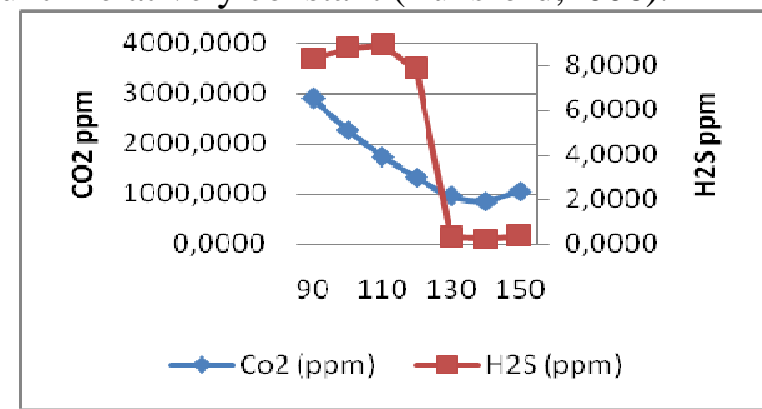

Figure 16The Correlation Between Amine Temperature inlet Contactor Column and Acid Gas Concentration Product 
MDEA solvent reacts with $\mathrm{CO}_{2}$ and when operated at lower temperatures will decrease the reaction rate constant, which means that a reduction in the rate of reaction of the amine absorption of $\mathrm{CO}_{2}$ will be reduced. The higher temperature increases the kinetic effect to a greater extent relative to the decrease in solubility. However, after a certain temperature, the solubility dominates the kinetics (Lunsford,2006). In addition, low temperatures cause $\mathrm{CO}_{2}$ slip. Thus, any change in temperature, will result in $\mathrm{CO}_{2}$ Slip that will affect the $\mathrm{CO}_{2}$ content in the sweet gas (Satyadileep et al, 2013).

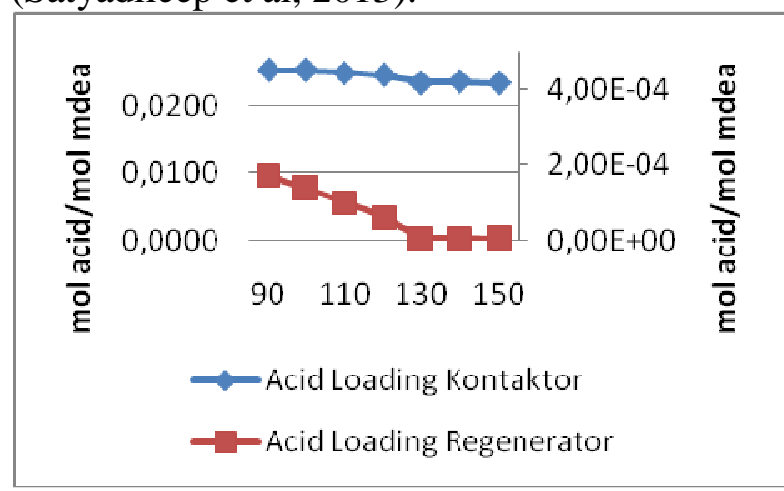

Figure 17The Correlation of Amine

Temperature inlet Contactor Column and Acid Loading in Contactor and Regenerator column

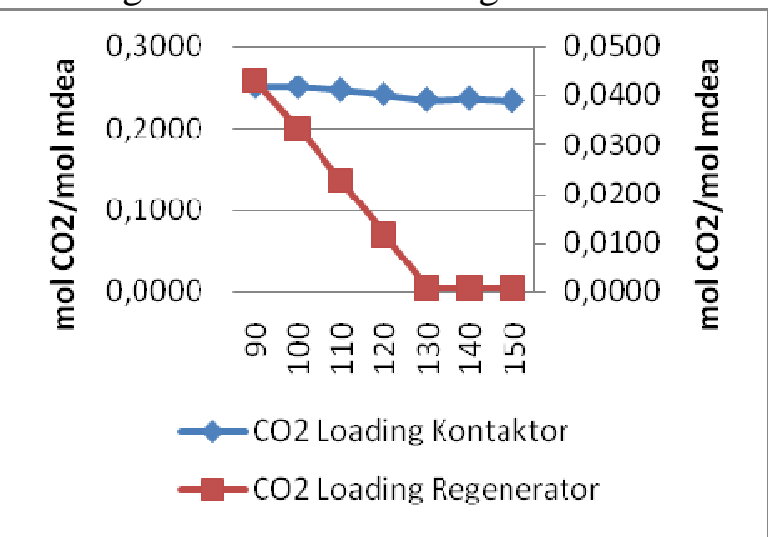

Figure 18 The Correlation of Amine

Temperature inlet Contactor Column and $\mathrm{CO}_{2}$ Loading in Contactor and Regenerator column

Based on Figure 17 and Figure 18 Shows the changes in acid gases and $\mathrm{CO}_{2}$ loading in rich amine and lean amine versus amine temperature inlet contactor column. Based on Figure 4.11 and Figure 4.12, Acid gas loading and $\mathrm{CO}_{2}$ loading decreased contactors tend to be stable. So that the temperature rise would not be so effective in reducing the content of $\mathrm{H}_{2} \mathrm{~S}$ in the sweet gas, it increased the $\mathrm{CO}_{2}$ absorbed the which is not preferable in the selective absorption process. If the amount of $\mathrm{CO}_{2}$ in acid gas feed of the unit was high, lower temperatures should be Considered for the operating temperature of the absorber column to absorb lower $\mathrm{CO}_{2}$. On the other hand, if the amount of $\mathrm{CO}_{2}$ in acid gas feed of the unit was low or negligible, Increasing temperature are allowed but More Temperatures should be prevented to avoid increasing of the $\mathrm{H}_{2} \mathrm{~S}$ concentration in the sweet gas stream in the top of the absorber (Mahdipoor, 2016).

\section{Conclusion}

According to the results of simulation, can be concluded as follows. There is no big different between design and simulation except $\mathrm{CO}_{2}$ in sweet gas. It is because of using MDEA while operating simulation. Meanwhile, Effect of Flow rate feed gas is increasing acid gas contains in sweet gas. It is because more flow rate, more acid gas contains in feed gas and there is not any effect on $\mathrm{H}_{2} \mathrm{~S}$ of sweet gas but increasing $\mathrm{CO}_{2}$ of sweet gas while increasing temperature of feed gas. It is probably there is hydrocarbon liquid while operate temperature more than $120{ }^{\circ} \mathrm{F}$.Increasing amine strength will reduce acid gas of sweet gas. More amine concentration, there is more reaction between amine and acid gas so that acid gas absorb widely and the effect of amine temperature is reducing acid gas concentration of sweet gas. Decreasing of acid gas due to increasing reaction rate constant.

\section{Acknowledgements}

This work were supported by Aditya Tri Atmaja and Moh Taufiq Anwar 


\section{DAFTAR PUSTAKA}

Abdel-Aal, H.K. and Anggour, M.A. 2003.Petroleum and Gas Field Processing. Marcel Dekker, Inc : New York

Alvis, R.S., Hatcher, N.A. and Weiland, R.H. 2012. CO2 Removal From Syngas Using Piparazine-Activated MDEA and a Potassium Dimethyl Glycinate. In Conference Nitrogen + Syngas. February 20-23 ${ }^{\text {th }} 2012$ :Athens, Greece.

Document JOB Pertamina - Medco E\&P Tomori Sulawesi. 2013. AGRU

Lunsford, K.M. and Bullin, J.A. 2006. Optimization of Amine Sweetening Unit.Bryan Research and Engineering, Inc.

Mahdipoor H.M. and Kakavand, M. 2015. The Effect of Amine Concentration on The Performance of TGT Absorber Column. ISSN 1337-7027 vol 57(1) pages 56-59.

Mahdipoor, H.M. 2016. Investigating The Effect Of Operating Temperature On The
Performance Of TGT Absorber Column. International Journal of Energy Science (IJES).Vol 6 Issue 1.

Mokhatab, S., Poe, W.A., Mak, J.Y. 2015.Handbook of Natural Gas Transmission and Processing:Principles and Practices. Gulf Professional Publishing: Oxford, UK.

National Renewable Energy Laboratory (NREL). 2009. Survey and DownSelection of Acid Gas Removal System for Thermochemical Conversion of Biomass to Ethanol with Detailed Analysis of an MDEA System. NexantInc: San Francisco, California.

Satyadileep, D, Berrouk, S and Peters C.J. 2013. Improve amine Unit Efficiency by optimizing Operating Conditions. Gas Pro Americas

Zurlo,J etc. 2013. Optimize amine units and improve refinery profitability. The Woodlands, Texas. Page 61-64 